$\left.\begin{array}{c}\text { Sournals } \\ \text { INTERNATIONAL JOURNAL OF } \\ \text { ORGANIZATIONAL LEADERSHIP }\end{array}\right) \begin{gathered}\text { INDUSTRIAL } \\ \text { MANAGEMENT } \\ \text { INSTITUTE }\end{gathered}$

\title{
Monitoring the graduates of PNU
}

\author{
Ali Nejatbakhsh Esfahani*, Seyed Ali Qureishian \\ Department of Management, Payame Noor University
}

\begin{tabular}{l}
\hline \\
Keywords: \\
Graduates, Higher \\
Education System, \\
Payame Noor University, \\
Monitoring, Employment \\
\hline Received \\
11 November 2016 \\
Received in revised form \\
29 February 2016 \\
Accepted \\
03 March 2017 \\
\hline
\end{tabular}

Correspondence:

Hany.orveh@gmail.com

\begin{abstract}
The current paper monitored the graduates of Payame Noor University (PNU) and the project has been done in the institute for open and distance learning. Most of the countries in the world deal with the issues of employment. The task is more complicated in the third world countries for the variety of factors, which some of them are unknown to the third world countries. Today, the country's macro management seek for scientific methods to identify and control the problematic factors in employment. Besides, they tend to convert challenges into opportunities to accelerate the development move. Universities and higher education institutions undertake missions such as knowledge production, training of specialised manpower needed by the society, technology development, innovation, and creativity. Nowadays, experts believe that sustainable development is only achieved through the application of modern knowledge and advanced technology. The labour market is one of the four markets defined in the economics that the presence of human factor differentiates it from other markets such as money market, capital market, and commodity market. Excess supply of manpower compared to its demand in the labour market is one of the main reasons of unemployment, especially youth unemployment. Thus, continuity of unemployment and its increasing double-digit rate over the past few decades in different countries reflects non-equilibrium in supply and demand and is a sign of structural problems of the market. In this research, after discussing the challenges and opportunities of higher education system in the employment of students, the effective factors are divided into two groups of internal and external factors. Finally, the demographic variables will be considered separately according to these factors.
\end{abstract}

(C)AIMI Journals

Among the main missions of the universities are the education of human resources, dissemination of knowledge, creativity, initiative, and innovation. The less developed a country, the more the expectations of its people from the universities. The reason is that in 
those countries, there are no other organisations to undertake the responsibilities of the universities. The fundamental reason for the failure of the universities in the third world countries is that the structure and function of them are modelled on older universities in industrialised societies. Many of National Developmental Programs of theses universities imitate the universities of developed countries (Bigdeli, Keramati, \& Bazargan, 2013). The more attention the authorities pay to career prospects in this field, the fewer people concern about it. Besides, students will perform confidently their duties which include learning lessons and preparing themselves for future jobs. Different experts emphasise on the critical role of the universities in the employment and job training courses, especially entrepreneurial skills training. Farahani and Bayat (2008) argue that the findings of the studies of many researchers show that the training of graduates in higher education is a necessity. Due to the damaging effects of unemployment, especially in the younger generation, achieving the full employment is considered as one of the most important goals of the government's twenty-year outlook document and 1404 vision. The government announced reducing the unemployment as the overall policy of the Fourth Plan of Economic, Social and Cultural Development of the Islamic Republic of Iran. Besides, the unemployment rate reduced in 2009 at 8.4\%. The balance of the labour market, especially for younger people, is faced with numerous obstacles. Therefore, identification of the obstacles and taking appropriate measures to overcome the issues are the preconditions of achieving the goals of employment and reducing the unemployment rate.

\section{The Literature Review}

At present, the higher education system in our country is the main centre for educating specialists. Yet, it cannot fulfil its purpose that is training specialists and job opportunities for them. The findings of several studies in this realm confirm the failure of the universities. The relationship between education and employment inspired by the human capital theory has changed from the extreme optimism of the 1960s to a caution and pessimism in 1990 (Salehi Omran, 2007).

Universities and higher education centres are responsible for missions such as knowledge production, training of specialised manpower needed by the society, technology development, innovation, and creativity. Today, experts believe that sustainable development is only achieved through the application of modern knowledge and advanced technology. In this regard, universities need to change their policy and train the students in a way that they can apply new technologies to their future career.

According to recent studies, in addition to the general factors of unemployment, the factors of unemployment of the higher education graduates in Iran can be divided into two categories, namely internal and external factors. Following this, internal factors are processes and strategies applied in higher education system. They are directly or indirectly linked with the issues of employment of graduates. The most important elements of these factors are disproportion between the current admission capacity of the universities and the future needs of the labour market; disproportion between the educational content and job skills; failure of the universities in promoting scientific spirit and motivation among students to serve the society; the minimum requirements of theoretical and practical knowledge of graduation is not assigned by the universities; unfamiliarity of faculty members with the real needs of the labour market; 
lack of appropriate context for scientific and practical training; inability of the faculty members in training specialised workforce needed by the society; and research is not a priority at the universities.

External factors involve all the elements that affect graduates' employment directly and indirectly. These factors state that employment culture is not specified or common. Other elements are underdevelopment of the private employment agencies; underdevelopment of the centres of graduates and their failure in performance and career guidance; multiplicity of applicants and intense competition for available jobs; lack of widespread entrepreneurial culture and entrepreneurs; and executive difficulties in implementing employment policies and Macro plans for employment.

Absorption of the university graduates and higher education centres to the labour market are subject to certain capabilities and features that some of them must be obtained during the period of study. It seems that the disproportion between the educational process and the materials taught at the universities with the skills and abilities needed in labour market is the most important factor of unemployment of the university graduates. It should be noted that in addition to aforementioned factors, a number of external factors, that are out of the control and activities of higher education system, have a significant influence on graduate employment.

In a report prepared by UNESCO it is noted that in response to the challenges of the changing labor world, it is expected from the higher education that first, there should be more diversity in terms of structure and link between economic conditions and course plans; second, more attention should be paid to general competencies, social skills, and personal developments; and third, regular methods of communication should be used between higher education and the labor world. Communication tools offered by UNESCO to overcome the problems of supply and demand for educated labor force include participation of employers in curriculum development, consideration of industrial training in the curriculum, making academic and professional courses, and part-time training for workers that are flexible, parttime jobs for students in projects that are implemented in industry, and preparation of career and employment services for graduate employment aid.

Salehi Omran (2007) considers the issue of employment of graduates in recent years in Iran as one of the challenges of economic, social, and cultural nature, and categorises it among the most important threats to security and national development.

Many studies have been conducted to describe the employment situation of graduates. For example, the findings of Mohammadzadeh's (2007) study show that $40 \%$ of the graduates of agriculture of Elmi-Karbordi universities are unemployed, 32\% have part-time jobs, $12 \%$ have full-time jobs, and 13\% are continuing their education. The results of Salehi Omran (2007) show that $57 \%$ of the female graduates of the University of Mazandaran work in unrelated fields of their major and $43 \%$ of them have not been able to find a job. From those who are employed, $62 \%$ work in the public sector, $34 \%$ in the private sector, and only $3 \%$ are selfemployed.

Results of the study by Khademi and Pour Haqiqizade (2005) show that more than $95 \%$ of the graduates of educational administration have been absorbed by the labour market, more than $90 \%$ of them are employed by the Education Organization, and very few of them are employed by other organisations or are unemployed. 
Regarding the great number of graduates of PNU in different majors and programs, the question arises that how successful they were in being employed and if they were, is their job related to their academic field of study?

\section{Research Questions}

The following research questions guided the study.

- $\mathbf{R Q}_{1}$ : What is the employment rate of the graduates?

- $\mathbf{R Q}_{2}$ : Is there a relationship between the employment of the graduates and their gender, age, and educational groups?

- $\mathbf{R Q}_{3}$ : Is there a relationship between the coordination of employment of the graduates and their gender, study program, and educational groups?

- $\mathbf{R Q}_{4}$ : What is the role of personal, organisational, and educational characteristics of employment of the graduates?

- RQ5: What is the role of internal factors in future employment?

- $\mathbf{R Q}_{6}$ : What is the role of external factors in future employment?

\section{Method}

The present study involves a large scope, periodical, applied and descriptive survey. The methodology of this study includes a detailed description of the population, sample, sample size, sampling, measurement tools, methods to assess their validity and reliability, the design of the research, research methodology, statistical methods of data analysis, and presented statistical tests. The main objective of the study is the evaluation of employment of graduates of PNU and its influencing factors in the period of 2009 to 2012. This general objective will be pursued through the following sub-goals including the determination of the employment rate of the graduates; determination of the relationship between graduates' employment with gender, age, and educational groups; the relationship of coordination between the employment of graduates and gender, study program, and educational groups; the role of personal, organisational, and educational characteristics in the employment of graduates; the effect of internal factors on the future employment of the students; and the effect of external factors on the future employment of the students.

The sample population of the study included all graduates of PNU between the years 2009 to 2012 and cluster sampling was used to select 320 cases among them. To analyse the data statistically, all the required data for the study were gathered through a researcher-made questionnaire. The questionnaire had seven demographic questions and 26 closed-answer questions.

In order to establish the validity of the study, apparent validity was used. The reliability of the study was established by the test-retest method. Following this, the reliability coefficient of the questionnaire was 0.917 . The closer this number to 1 , the more stability of the questions.

The population sample of the study included all PNU graduates between the years 2009 to 2012. Due to the lack of specific sampling frame (lack of a list of the names of students according to their province, city, major, and program) cluster sampling method was used. Seven clusters were selected according to the density of the students in different branches 
across the country as a sample of other nearby branches. The sample size using the Cochran formula was estimated 396 people.

76 questionnaires were incomplete to be processed in data analysis. Hence, statistical analysis was performed using 320 questionnaires.

$$
n=\frac{\delta_{x}{ }^{2} z^{2} \frac{\alpha}{2}}{e^{2}}
$$

Formula 1. Cochran formula

\section{Results}

Descriptive analysis was used in the study. Frequency tables and statistical graphs were designed to collect general information on the sample cases. Then frequency tables were used for every question and its related hypothesis. In these tables, the frequency of answer to each question is listed along with its mean and standard deviation. In the inferential analysis section, Friedman rating tests and Chi-square tests were used to answer the research questions as shown in Table 2. Table 1 shows the statistical tests used in the study.

Table 1

Statistical Tests Used

\begin{tabular}{|c|c|c|}
\hline Row & Research questions & Statistical Test \\
\hline 1 & What is the employment rate of graduates? & Chi-Square \\
\hline 2 & $\begin{array}{l}\text { Is there a relationship between the employment of graduates and their sex, age and } \\
\text { educational groups? }\end{array}$ & Chi-Square \\
\hline 3 & $\begin{array}{l}\text { Is there a relationship between the coordination of employment of graduates and their } \\
\text { gender, study program and educational groups? }\end{array}$ & Chi-Square \\
\hline 4 & $\begin{array}{l}\text { What is the role of personal, organisational and educational characteristics of } \\
\text { employment of graduates? }\end{array}$ & \\
\hline 5 & What is the role of internal factors in future employment? & Friedman Test \\
\hline 6 & What is the role of external factors in future employment? & Friedman Test \\
\hline
\end{tabular}

The collected data are the main source of information for the researcher to answer the research questions. Considering the nature, structure, and form of the hypothesis, the researcher faced with the question of how to classify, analyse, and finally process the data to evaluate the research hypothesis that are the possible and temporary answers to research questions. There are a variety of ways to analyse the data, according to their nature that the researcher must pay attention to the application and appropriateness of these methods to eventually be able to make concise valid inferences and conclusions. Table 2 presents the frequency of the participants by gender. 
Table 2

Frequency of the Participants by Gender

\begin{tabular}{lcccc}
\hline & Frequency & Percentage & Valid Percent & Cumulative Percentage \\
\hline Female & 184 & 55.7 & 60 & 60.5 \\
Male & 120 & 37.5 & 39.5 & 100 \\
Total & 304 & 95 & 100 & \\
Missing Data & 16 & 5 & \\
Final Total & 320 & 100 & \\
\hline
\end{tabular}

As Table 2 shows, 184 of the participants were female at $57.5 \%$ and 120 of them were male at $37.5 \%$ and about $5 \%$ of the participants did not mention their gender.

Personal characteristics variable for finding a job is made up of four items measured on a 5option Likert scale. The mean of these three variables was 3.78 with a standard deviation of 0.78. The negative coefficient of Skewness of this distribution suggests that its Skewness is negative. In other words, most participants of the study have given high marks to this variable. Table 3 shows the relationship between organisational characteristics and job finding.

Table 3

The Role of Organisational Characteristics to Find a Job

\begin{tabular}{|c|c|c|c|c|c|c|}
\hline & $\begin{array}{l}\text { The Role of } \\
\text { Employment Laws } \\
\text { to Find a Job }\end{array}$ & $\begin{array}{l}\text { The Role of } \\
\text { Economic Policy to } \\
\text { Find a Job }\end{array}$ & $\begin{array}{c}\text { The Role of Supply and } \\
\text { Demand of Job to Find a } \\
\text { Job }\end{array}$ & $\begin{array}{l}\text { The Role of Knowledge, } \\
\text { Skill and Attitude Trained in } \\
\text { Universities in Finding a Job }\end{array}$ & Mean & SD \\
\hline Very Low & 3.8 & 11.3 & 6.3 & 10.8 & & \\
\hline Low & 6.4 & 17 & 14.5 & 13.3 & & \\
\hline Average & 22 & 30.8 & 28.9 & 30.4 & & \\
\hline Much & 36.5 & 21.4 & 32.1 & 27.2 & 3.29 & 0.93 \\
\hline Very Much & 31.4 & 19.5 & 18.2 & 18.4 & & \\
\hline
\end{tabular}

The variable of the role of organisational features to find a job consisted of four items measured on a 5-option Likert scale. The mean of these three variables was 3.3 with a standard deviation of 0.93 . The negative coefficient of Skewness of this distribution suggested that its Skewness was negative. In other words, most participants of the study have given high marks to this variable.

\section{Answers to the Research Questions}

- $\quad \mathbf{R Q}_{1}$ : What is the employment rate of graduates?

Table 4 which shows the test of employment of the graduates assisted the researcher in answering the first research question.

Table 4

Test of Employment of the Graduates

\begin{tabular}{ccccccc}
\hline & Observed Frequency & Expected Frequency & Remainder & Chi-Square & df & Sig \\
\hline Yes & 88 & 79.5 & 8.5 & & & \\
No & 71 & 79.5 & -8.5 & 1.81 & 1 & 0.17 \\
Total & 159 & & & & & \\
\hline
\end{tabular}


Based on the descriptive table, $55 \%$ of the participants in the study were employed and the remaining $45 \%$ were unemployed. Chi-square test is a non-parametric statistical test and was used to assess if the nominal variables were analogous. According to the statistics of Chisquare test, the null hypothesis was confirmed and it is concluded that there was no sufficient evidence to confirm the existence of the difference at the population level.

- $\mathbf{R Q}_{2}$ : Is there a relationship between the employment of graduates and their sex, age, and educational groups?

Table 6 shows the relationship between employment and gender.

Table 5

Test of Relationship between Employment and Gender

\begin{tabular}{|c|c|c|c|c|c|c|c|c|}
\hline & & & \multicolumn{3}{|c|}{ Gender } & \multicolumn{3}{|c|}{ Test } \\
\hline & & & Female & Male & Total & Chi-square & $\mathrm{df}$ & Sig \\
\hline \multirow{6}{*}{$\begin{array}{l}\text { Are you } \\
\text { currently } \\
\text { employed? }\end{array}$} & Yes & Frequency & 78 & 92 & 170 & \multirow{6}{*}{16.79} & \multirow{6}{*}{1} & \multirow{6}{*}{0} \\
\hline & & Percent & $42.9 \%$ & $76.7 \%$ & $56.3 \%$ & & & \\
\hline & No & Frequency & 104 & 28 & 132 & & & \\
\hline & & Percent & $57.1 \%$ & $23.3 \%$ & $43.7 \%$ & & & \\
\hline & \multirow[t]{2}{*}{ Total } & Frequency & 182 & 120 & 302 & & & \\
\hline & & Percent & $100 \%$ & $100 \%$ & $100 \%$ & & & \\
\hline
\end{tabular}

Based on the Table 5, about $77 \%$ of men and $43 \%$ of women announced that they are employed. Chi-square test is a non-parametric statistical test and was used to assess if the nominal variables were analogous. According to statistics of Chi-square test (value $=16799$, df $=1$, sig $=.000$ ), the null hypothesis that there is no difference between male and female graduates in the population was rejected. It can be concluded that there is a difference between male and female graduates.

- $\quad \mathbf{R Q}_{3}$ : Is there a relationship between the coordination of employment of the graduates and their gender, study program, and educational groups?

Table 6 and 7 will assist the researcher in answering the third research question.

Table 6

Test of Relationship between Employment and Educational Group

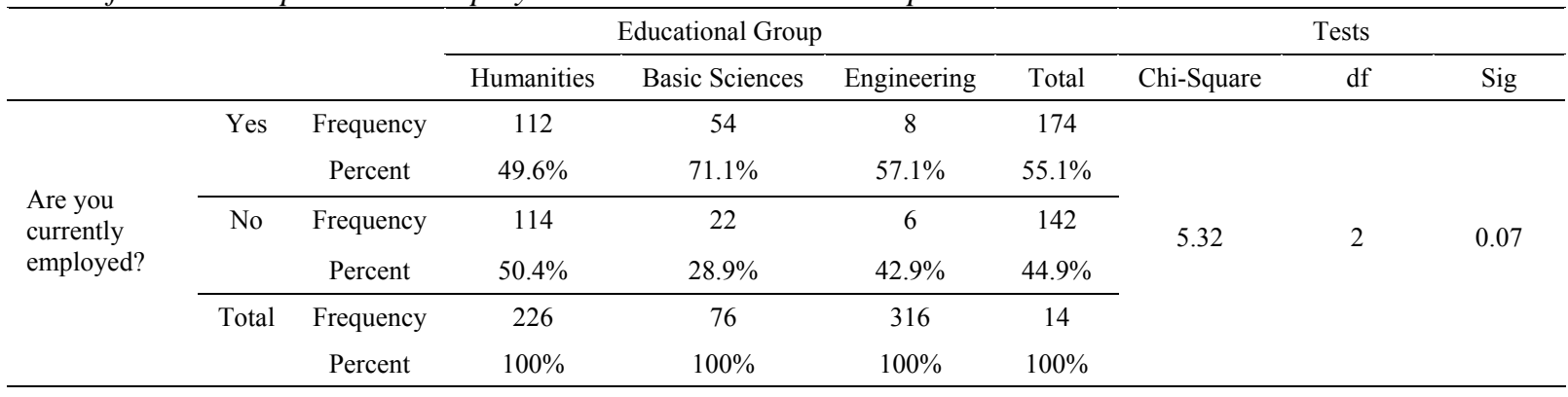

Based on the above table, $64 \%$ of the graduates of humanities, $71 \%$ of the graduates of basic sciences, and $57 \%$ of the graduates of engineering have stated that at the time of completing the questionnaire they were employed. Chi-square test is a non-parametric statistical test and was used to assess if the nominal variables were analogous. According to the statistics of Chi- 
square test (value $=16799, \mathrm{df}=1$, sig $=.000$ ), the result was not sufficient to reject the null hypothesis. Therefore, the null hypothesis which claims that there is no difference between different educational groups of graduates was confirmed and it was concluded that any difference is simply due to chance.

Table 7

Test of Coordination of Employment and Educational Group

\begin{tabular}{|c|c|c|c|c|c|c|c|c|c|}
\hline & & & \multicolumn{4}{|c|}{ Group } & \multicolumn{3}{|c|}{ Tests } \\
\hline & & & Humanities & $\begin{array}{c}\text { Basic } \\
\text { Sciences }\end{array}$ & Engineering & Total & Chi-Square & $\mathrm{df}$ & Sig \\
\hline \multirow{8}{*}{$\begin{array}{l}\text { Coordination } \\
\text { between Job } \\
\text { and } \\
\text { Educational } \\
\text { Major }\end{array}$} & Yes & Frequency & 40 & 26 & 2 & 68 & \multirow{8}{*}{3.13} & \multirow{8}{*}{4} & \multirow{8}{*}{0.53} \\
\hline & & Percent & $31.2 \%$ & $44.8 \%$ & $20 \%$ & $34.7 \%$ & & & \\
\hline & Somehow & Frequency & 46 & 16 & 6 & 68 & & & \\
\hline & & Percent & $35.9 \%$ & $27.6 \%$ & $60 \%$ & $34.7 \%$ & & & \\
\hline & No & Frequency & 42 & 16 & 2 & 60 & & & \\
\hline & & Percent & $32.8 \%$ & $27.6 \%$ & $20 \%$ & $30.6 \%$ & & & \\
\hline & \multirow[t]{2}{*}{ Total } & Frequency & 128 & 58 & 10 & 196 & & & \\
\hline & & Percent & $100 \%$ & $100 \%$ & $100 \%$ & $100 \%$ & & & \\
\hline
\end{tabular}

Based on the Table 7, 31\% of the graduates of humanities, $45 \%$ of the graduates of basic science, and $20 \%$ of the engineering graduates has mentioned that their job coordinates with their field of study. Chi-square test is a non-parametric statistical test and was used to assess if the nominal variables were analogous. According to the statistics of Chi-square test (value = 3.134 , $\mathrm{df}=4 \mathrm{sig}=.536$ ), the null hypothesis that claims there is no such difference was confirmed. Accordingly, it seems that this difference was due to the elements of chance.

- $\mathbf{R Q}_{3}$ : What is the role of personal, organisational, and educational characteristics of employment of graduates?

The aim of Friedman test is to prioritise and rank the variables based on the greatest impact on the dependent variable. This test is for randomised complete block design that is called after its creator, the famous economist Milton Friedman. This test is actually an extension of the sign test for two treatments. In other words, Friedman test is equal to sign test. This test is used to compare a number of groups regarding their average ratings and it determines whether these groups can be the same population or not. This test is used to test hypotheses that have been obtained from a number of measurements. To calculate the Friedman test, dependent variables per person need to be arranged and then the average ratings need to be compared. Table 8 shows the relationship between the role of personal, organisational, and educational characteristics and job finding.

Table 8

Test of the Role of Personal, Organisational and Educational Characteristics of Employment of Graduates

\begin{tabular}{lcccc}
\hline & Average Ratings & Chi-Square & Degree of Freedom & Significance \\
\hline The Role of Personal Characteristics in Finding a Job & 2.55 & 11.89 & 2 & 0 \\
The Role of Organisational Characteristics in Finding a Job & 2.04 & & & \\
The Role of Educational Characteristics in Finding a Job & 1.41 & & & \\
\hline
\end{tabular}

Regarding the fact that the average rating of the variable "the role of personal characteristics in finding a job" is more than the other two variables, it can be concluded that the role of 
personal characteristics is more important than the role of organisational and educational characteristics. This finding is confirmed by $99 \%$ (Value $=111.89, \mathrm{df}=2 \mathrm{sig}=.000)$.

\section{Discussion and Conclusion}

Every study is a rational, organised scientific effort to answer a question or to find a solution to a problem. Every method used in different studies has its own benefits. The main findings of the current study are accepting or rejecting the hypotheses. The hypotheses are either rejected or confirmed (not proven). These two states create knowledge for researchers. In conclusion, the researchers find out in what ways the problem can be solved.

From a total number of 320 participants in the study, 112 people $(35 \%)$ were graduated in 2012 and only two people $(0.6 \%)$ were graduated in 2006; in addition, 228 people $(71 \%)$ were graduated in Humanities, $24 \%$ in science, and 14 people $(0.4 \%)$ in engineering; also, 242 people $(78 \%)$ were studying in the undergraduate program and 68 people ( 22 percent) in the graduate program; following this, 182 people $(57 \%)$ were single at the time of graduation and 136 people (43\%) were married; moreover, 176 people (55\%) were employed at the time of the study and 142 people (45\%) were unemployed; and the field of the study of 70 people $(35 \%)$ matched their job, 68 people (34\%) somehow matched, and 31\% did not match at all.

The Variable of personal characteristics in finding a job contains three items that are measured in 5-option Likert scale. The average of these three variables on the scale of 5 is 3.78 with a standard deviation of 0.78 . The variable of the role of organisational characteristics in finding a job consists of four items that are measured on a 5-option Likert scale. The average of the three variables on the scale of 5 is 3.3 with a standard deviation of 0.93 . The variable of the role of educational characteristics in finding a job consists of 8 items that are measured on a 5option Likert scale. The average of the three variables on the scale of 5 is 2.77 with a standard deviation of 0.73 . The variable of "disproportion between the current capacity for university admissions and the labour market needs" is one of the five internal factors affecting the students' employment. The most persistent factor of this distribution is the first priority.

The variable of "mismatch between the content of academic courses and job skills" is one of the five internal factors influencing the students' employment. The most frequent factor of this distribution is the first priority.

"The inability of the educational system to create employment spirit" is also considered as one of the five internal factors impacting the students' employment. The most repeated factor of this distribution is the third priority. Following this, the variable of "unfamiliarity of the graduates and faculty members with employment needs" is one of the five internal factors affecting the students' employment and the most frequent factor of this distribution is the third priority.

"The inefficiency of the employment systems" tends to be one of the five internal factors impacting the students' employment. The most recurrent factor of this distribution is the third priority. Moreover, "the weakness of employment culture in the society" is one of the five external factors affecting the students' employment that the most frequent factor of this distribution is the third priority.

In addition, "the lack of employment agencies" is one of the five external factors influencing the students' employment that the most frequent factor of this distribution is the 
fourth priority. "The lack of associations and unions of graduates" is one of the five external factors affecting the students' employment and the most occurring factor of this distribution is the fifth priority. Furthermore, "the abundance of university graduates" tends to be one of the five external factors impacting the students' employment and the most frequent factor of this distribution refers to the first priority. Finally, the variable of "administrative problems in the employment policy" is one of the five external factors affecting the students' employment that its most frequent factor is the first priority. Male and female graduates consider the "disproportion between students' admission capacity and labour market needs" as the most important internal factor in the employment of graduates.

Graduates of humanities, science, and engineering consider the following internal factors, namely "disproportion between students' admission capacity and labour market needs" and "inefficiency of employment systems" as the most important problems in the employment of graduates. Graduates of bachelor and master programs, consider the "disproportion between students' admission capacity and labour market needs" as the most important factor in the employment of graduates. Male and female graduates consider "the abundance of university graduates" and "weakness of employment culture in the society" as the most important problems in the employment of the graduates, respectively.

Graduates of humanities, science, and engineering regard the following external factors, namely "the abundance of university graduates", "administrative problems in the employment policy", and "lack of employment agencies" as the most important problems in the employment of graduates, respectively. Graduates of bachelor and master programs consider the "administrative problems in the employment policy" and "the abundance of university graduates" as the most important external factor in the employment of graduates. Following this, $55 \%$ of the participants in the study were employed and $45 \%$ of them were unemployed. According to the statistics, the null hypothesis Chi-square test is confirmed and it is concluded that there is no sufficient evidence to confirm a difference at the population level. Besides, $77 \%$ of men and $43 \%$ of women stated that they are employed. The null hypothesis that claims there is no difference between male and female graduates is rejected and it can be concluded that there is also a difference at the population level. In addition, 64\% of the graduates of humanities, $71 \%$ of the graduates of basic sciences, and $57 \%$ of the graduates of engineering have announced that they were employed at the time of completing the questionnaire. According to the statistics of Chi-square test, the statistics are not sufficient to reject the null hypothesis. Therefore, the null hypothesis that claims there is no difference between different educational groups of graduates is confirmed and it is concluded that any difference is simply due to the elements of chance. About $50 \%$ of the graduates of bachelor programs and $79 \%$ of master's graduates have announced that they were employed at the time of completing the questionnaire. According to the statistics of Chi-square test, the null hypothesis that claims there is no difference between different programs of graduates is rejected. About $29 \%$ of male graduates and $38 \%$ of female graduates announced that their subject of academic study matches their jobs. According to the statistics of Chi-square test, the null hypothesis that claims there is no such difference is confirmed. Accordingly, this difference is considered to be due to the elements of chance and accident. About $45 \%$ of the graduates in basic science and $20 \%$ of the graduates in engineering claimed that their field of study matches their jobs. According to the 
statistics of Chi-square test, the null hypothesis that claims there is no such difference is confirmed. On this basis, the difference is considered due to the elements of chance and accident. About $30 \%$ of the graduates of bachelor programs and $52 \%$ of the graduates of master programs claimed that their jobs match their academic education. According to the statistics of Chi-square test, the null hypothesis that claims there is no such difference is confirmed. On this basis, any difference is considered due to the elements of chance and accident. Compared to other variables, the mean scores of the variable "the role of personal characteristics to find a job" is higher than the others. The role of personal characteristics is more important than organisational and educational characteristics. This is confirmed by $99 \%$ of confidence level. Among the internal factors, "disproportion between students' admission capacity and labour market needs" has the highest priority and the items of "unfamiliarity of graduates and faculty members with employment needs" and "inefficiency of employment systems" have the lowest priority. Friedman test was used for hypothesis testing. The result shows that the null hypothesis is verified and any discrepancies are due to the elements of chance. Among the external factors, "administrative problems in the employment policy" has the highest priority and "lack of associations and graduation centres" has the lowest priority. Friedman test was used for hypothesis testing. The result shows that the null hypothesis is rejected at the $99 \%$ confidence level.

Although, Statistical Center of Iran recently reported that the legend households' population growth in the $60 \mathrm{~s}$, never repeated in the $70 \mathrm{~s}$ to $90 \mathrm{~s}$, the maximum age of 31 years old of the people in the labour market reflects the continuous inflation of the young population in Iran. Currently, $31.4 \%$ of Iran's population are men between the age of 15 to 29 years old and $31.7 \%$ are women in the same age group.

One of the first demands of every university graduates is to have a proper job; but, what we face nowadays is a wave of unemployed graduates. The university-educated labour force is generally supplied by the state, and in most cases, there is no competition between universities and students. As a result, there is no motivation for students to compete with others in scientific areas. The policy of employment of the state agencies makes the situation even worse. On the one hand, most of the educated people are supposed to be absorbed by the state agencies and on the other hand, state agencies do not care the quality of the education of the volunteers. In fact, it is the nature of relationships that selects the applicants. Another problem is that the absorption of graduates of universities and centres of higher education in the labour market depends on the capabilities and characteristics that some of them should be established during studying at the university. It seems that the mismatch between the educational materials of fields of study at the universities and the skills and competencies required by the labour market is the most important reason that graduated are not successful in employment. Besides, some external factors that are not included in activities or under the control of higher education have a significant impact on the employment of graduates. Factors affecting the employment of graduates are divided into two categories including internal and external factors. Internal factors are processes and strategies that are applied in the higher education system and directly or indirectly link with the issue of employment of graduates. External factors include all factors that directly or indirectly affect the employment of graduates and prevent their absorption in 
the labour market. Creation of spurious careers and working in professions that are irrelevant to the educational field result in a lack of development in the country.

One of the most important reasons for the increase of unemployment among graduates is that the training courses at the universities do not match with the needs of the labour market. Abstract textbooks of the universities and their mismatch with the requirements needed by the labour market are other important reasons that provoke unemployment. Learning different professions and gaining expertise in various fields during education could reduce the economic and psychological burden of unemployment of the graduates. From this perspective, it must be clarified that the training of workforce is still the missing link in the country's educational system. If authorities pay serious attention to long-term programs of training students during their education, there will be less harmful consequences of unemployment among university graduates.

Modern society needs people who are determined to achieve success, able to turn dreams into reality, and have a spirit of autonomy to explore new opportunities. If we pay sufficient care to the economic and social impact of entrepreneurship, the role of professionals and graduates in the development of a society will be cleared and graduates will respond to different needs of society. When the majority members of a society accept entrepreneurship as a career, it grows rapidly, such that entrepreneurship will lead to new jobs and reduces unemployment rate. Based on research of Saeedi Rezvani, Mohammad Hosseinzadeh, and Bagh Goli (2011), this issue was reflected in our university community. Yet, the arrangements of making students familiar with the labour market needs and other necessary preparations were never before considered at the universities.

Fifty-five percent of the participants in the study were employed and $45 \%$ of them were unemployed. The findings of the study are line with the findings of Salehi Omran (2007) and Saeedi Rezvani, Mohammad Hosseinzadeh, and Bagh Goli (2007). A significant correlation between the two variables of acquired capabilities and the hope of employment in the future was found out. In other words, the more the abilities of a person, the more their hoping of being employed, and vice versa.

Future studies require establishing the entrepreneurship centres and the Government move for culturalization in this area; reviewing and adjusting the training courses and topics based on related career fields; defining the standard criteria for evaluating the least theoretical knowledge and practical abilities of graduates at different fields of the study; defining the privacy of the universities and educational centres in order to prevent the penetration, abuse, and exploitation of influential political groups; and determining the university admission capacity based on the future needs of the labour market. In addition, the experience of giving the comprehensive exam to assess students in some fields of study (e.g. medical science) has caused their continuing education be conditioned to receiving a passing grade. Thus, when they enter the society as scientists and physicians, they are more successful both in education and in health care. Therefore, it is necessary to define standard educational topics for every course. Besides, some criteria need to be defined in order to assess the graduates and determine their minimum theoretical knowledge and practical ability. 


\section{References}

Bigdeli, M., Keramati, M. R., \& Bazargan A. (2013). A review of the relationship between the field of study and employment status of graduates. Journal of Research and Planning in Higher Education, 18(3), 111-131.

Farahani, A., \& Bayat, F. (2008). Job expectations of physical education students from career and their future employment in Khorasan Razavi Province. Rouyesh Journal, 5(19), 33-40.

Khademi, M., \& Pourhaghighizadeh, M. B. (2005). Assessing the usefulness of main and specialised courses of management major according to the graduates of Shiraz University working in education office. Research in Curriculum, 1, 43-56.

Mohammadzadeh, M., Pezeshkirad, G. R., \& Chizari, M. (2007). Employment status, job ability, and job success of graduates of agriculture of applied science university. Research \& Planning in Higher Education, 1(12), 79-98.

Saeedi Rezvani, M., Mohammad Hosseinzadeh, M., \& Bagh Goli, H. (2011). The future jobs of graduates of the faculty of educational sciences and psychology of the Ferdowsi University of Mashhad. Studies in Education \& Psychology, 11(2), 57-86.

Salehi Omran, I. (2007). The employment situation of female graduates: A case study. Research \& Planning in Higher Education, 12(2), 41-60. 